\title{
Os desafios do acesso aos medicamentos para o tratamento das doenças raras
}

Mauro Yoshitsugu SOKEI: Faculdade de Saúde Pública - FSP, Universidade de São Paulo - USP. ORCID: 0000-0002-5973-1102

Jaqueline Vilela BULGARELLI: Faculdade de Saúde Pública - FSP, Universidade de São Paulo USP. ORCID: 0000-0001-7810-0595

Recebido: 4 out. 2020

Aceito: 21 out. 2020

Autor de correspondência: Karen Pereira de Carvalho Passos

kpereirapassos@gmail.com

Conflito de interesses:

Os autores declaram não haver nenhum interesse profissional ou pessoal que possa gerar conflito de interesses em relação a este manuscrito.

\section{Resumo}

Para a União Europeia, doenças raras são aquelas que afetam menos de 5 em 10.000 pessoas. Embora individualmente raras, considerando que existem entre 6.000 e 8.000 tipos diferentes destas enfermidades, coletivamente, acometem de 6 a $8 \%$ da população, ou seja, entre 27 e 36 milhões de pessoas. No Brasil, de acordo com a Portaria no 199/2014, para ser classificada como rara, a doença deve atingir até 65 pessoas em cada 100 mil indivíduos. Estima-se que 13 milhões de brasileiros sofram destas condições e, no mundo, 420 milhões. Doenças raras são graves, crônicas, progressivas, degenerativas, incapacitantes, limitantes e trazem risco à vida. Para muitas delas, não existe cura e as opções terapêuticas são restritas, o que as tornam um grave problema de saúde pública. Poucos são os especialistas no assunto. Tal fato suscita o desamparo dos pacientes e seus familiares, tendo como principal consequência o atraso e a imprecisão no diagnóstico e tratamento da doença. $O$ custo do tratamento medicamentoso é sensivelmente mais elevado se comparado ao de outras enfermidades pois os valores investidos em pesquisa e desenvolvimento se assemelham aos empregados em doenças comuns, com a particularidade de que se destinam a menos pacientes, limitando a sua lucratividade. O Estado, por meio da CF de 1988 e art. $7^{\circ}$ da Lei Federal n. 8.080/1990, reconhece o direito à universalidade, equidade e integralidade aos serviços e ações de saúde. Porém, ao mesmo tempo que reconhece, dada as limitações dos recursos orçamentários, não consegue atender às demandas da população, em particular, as dos medicamentos para doenças raras, tendo como reflexo o aumento da judicialização como meio recorrente de acessá-los. Assim, há a necessidade da elaboração de uma política pública a fim de que o judiciário seja instado a intervir apenas em casos específicos. Nesse sentido, a CONITEC pode ser apontada como um instrumento estratégico para mitigar estas tensões. Assim sendo, é importante que suas decisões sejam tomadas com total autonomia. Há que se destacar, entretanto, que em função do alto custo das drogas, escassez de evidências científicas de eficácia, existe uma singular dificuldade na avaliação de incorporação. Esta dificuldade também é percebida em países da Europa e Canadá pois a avaliação econômica não deve considerar apenas o custo do tratamento, mas também os aspectos pessoais, sociais e os benefícios econômicos. No Canadá, há um envolvimento ativo do público e as opiniões dos pacientes têm sido levadas em consideração nos processos de avaliação. Por fim, é importante também trazer para a reflexão sobre o que diz a OMS: "A visão dos Objetivos de Desenvolvimento Sustentável é um mundo no qual ninguém fica para trás, incluindo pessoas que sofrem de doenças raras. Só porque uma doença afeta um pequeno número de pessoas não a torna irrelevante ou menos importante que as doenças que afetam milhões". O objetivo do estudo será explorar os caminhos e desafios dos portadores de doenças raras no acesso ao tratamento medicamentoso e os consequentes impactos nos recursos financeiros do sistema de saúde. 
Método: Como método de pesquisa foi utilizada a revisão integrativa da literatura. A pergunta norteadora foi: "Quais são os desafios dos pacientes com doenças raras no acesso ao tratamento medicamentoso por meio do sistema de saúde?". A partir da seleção dos descritores no DeCS (Principais: Doenças Raras, Doenças Órfãs, Anomalias Congênitas, Custos de Medicamentos, Tomada de Decisões, Política Nacional de Medicamentos, Acesso aos Serviços de Saúde, Gestão em Saúde, Políticas Públicas de Saúde, Política de Saúde, Sistemas de Saúde, Medicina Estatal, Sistema Único de Saúde) e MeSH (Principais: Rare Diseases, Congenital Abnormalities, Metabolism, Inborn Errors, Pharmaceutical Services, Health Services Accessibility, Drug Costs, National Health Programs, Health Policy, Health Services), foram feitas buscas nas bases de dados do BVS, Scielo, PubMed e Scopus no período de junho a setembro de 2020. Com relação à sintaxe para busca, os principais descritores utilizados para cada uma das 3 expressões foram: "Doenças Raras", "Drogas Órfãs e "Custos de Medicamentos" (População Medicamentos para Doenças Raras); "Política Nacional de Medicamentos", "Tomada de Decisões" e "Qualidade, Acesso e Avaliação da Assistência a Saúde" (Fenômeno Acesso) e "Sistema de Saúde", "Política de Saúde" e "Sistema Único de Saúde" (Contexto Sistema de Saúde). Com base nas combinações de buscas realizadas por meio dos operadores booleanos AND e OR, chegouse a um resultado de 3.744 artigos. Os artigos escolhidos tiveram como critério de inclusão e exclusão a pertinência e a adequação ao tema em pesquisa. Assim, dos 3.744 artigos iniciais foram excluídos 52 duplicados, sendo 30 por meio da ferramenta Zotero e 22 manualmente, uma vez que, inicialmente, não haviam sido identificados pela ferramenta. Adicionalmente, foram excluídos 3.329 artigos após a análise dos títulos e 319 após a leitura dos resumos, restando até o momento, 44 elegíveis para a leitura completa. Resultados preliminares: os artigos analisados exploraram as barreiras do acesso aos medicamentos para doenças raras, suas causas e as alternativas encontradas pelos pacientes para acessálos, tendo como consequência, o crescente impacto no sistema de saúde. A mitigação desta tensão passa pela CONITEC, que tem enfrentado um grande desafio na avaliação para incorporação destes medicamentos devido ao seu alto custo e a falta de evidências científicas que comprovem a sua eficácia. Verificou-se que esta questão não se restringe ao Brasil, pois estende-se também aos países da Europa e Canadá. Considerações finais: as leituras dos artigos realizadas até o momento têm evidenciado a relevância do tema em estudo, na medida em que há um aumento crescente da judicialização como meio de acesso ao tratamento medicamentoso para doenças raras. É preciso, portanto, que haja uma profunda reflexão sobre o dilema entre o atendimento do acesso universal à saúde, previsto na Constituição, e os limitados recursos orçamentários dos entes públicos.

Descritores: Doenças Raras; Custos de Medicamentos; Acesso a Medicamentos e Tecnologia em Saúde; Política de Saúde; Sistema Único de Saúde.

Keywords: Rare Diseases; Drug Costs; Access to Essential Medicines and Health Technologies; Health Policy; Unified Health System.

Palabras-claves: Enfermedades Raras; Costos de los Medicamentos; Acceso a Medicamentos Esenciales y Tecnologías Sanitarias; Política de Salud; Sistema Único de Salud. 